\title{
Ética de las relaciones sexuales y amorosas
}

\author{
Ethics of sexual and loving relationships
}

Félix López Sánchez ${ }^{1}$

Universidad de Salamanca

Recibido: $18-05-17$

Aceptado: $01-06-17$

\section{Resumen}

El presente artículo propone bases éticas que debieran sustentar las relaciones amorosas y sexuales de las personas. Para ello se parte del respeto a los principios de la libertad, la dignidad y la igualdad entre los miembros de la pareja. Se complementa la propuesta con procedimientos generales y específicos para aplicar dichos principios centrados en la ética del consentimiento y de la igualdad.

Para la construcción de una ética del consentimiento se ofrece un Programa que busca desarrollar ciertas competencias en base a unidades didácticas que contienen objetivos y contenidos, así como actividades y formas de evaluación.

Palabras clave: Ética del consentimiento, libertad, dignidad, igualdad.

\begin{abstract}
The present article proposes ethical bases that should support the amorous and sexual relations of the people. This is based on respect for the principles of freedom, dignity and equality between the members of the couple. The proposal is supplemented by general and specific procedures for applying these principles, which focus on the ethics of consent and equality. For the construction of an ethics of consent, a Program is offered that seeks to develop certain competences based on didactic units that contain objectives and contents, as well as activities and forms of evaluation.
\end{abstract}

Keywords: Ethics of consent, freedom, dignity, equality.

\footnotetext{
1.Universidad de Salamanca, España. Email: flopez@usal.es
} 
La secularización de la sociedad ha conllevado el abandono de la moral sexual judeocristiana que, como es sabido, solo legitima la actividad sexual en el matrimonio heterosexual con fines procreativos. Este abandono, que también han hecho la mayor parte de los creyentes, no ha sido sustituido por valores y principios éticos humanistas (Iribartren, 2002; Cortina, 2010). Son las clases dominantes de esta sociedad liberal de mercado las que publicitan valores y normas que han convertido también la sexualidad en un producto más de consumo. La obligación de consumir sexualidad y el discurso individualista sobre el placer, han convertido las relaciones sexuales, con frecuencia, en un campo de minas (Beck y Beck, 1999; Seligman, 2011).

Esto hace necesario y urgente elaborar una ética de las relaciones amorosas. Una ética socrática, de la buena vida, del placer y el bienestar, que respeta la libertad, dignidad e igualdad de la pareja. La hemos fundamentado en diferentes corrientes éticas (López, 2015) y desarrollado en unos principios y unidades didácticas (López, 2017): ética del consentimiento, ética de la igualdad entre los sexos, ética del placer y el bienestar compartidos, ética de la lealtad, ética de la salud, ética de la diversidad y ética de los cuidados a la pareja y a los hijos e hijas.

En esta breve publicación recogemos solo una parte de la ética del consentimiento.

\section{1.- Procedimientos generales para aplicar los principios.}

El primero de los procedimientos fue propuesto por Kant (1785): "Obra de tal modo que uses la humanidad, tanto en tu persona como en la persona de cualquier otro, siempre como un fin al mismo tiempo y nunca solamente como un medio" (pág. 65,66).

No instrumentalizar, explotar, cercenar la libertad y la dignidad de ti mismo y del otro. Somos valiosos y nunca un mero medio para un fin. Algunos ejemplos en el campo de la sexualidad y las relaciones amorosas: Usar a otra persona para tener actividad sexual con ella, sin respetarla, tenerla en cuenta, tomarla en serio, etc. Violar, acosar, abusar de menores, engañar, usar cualquier forma de coerción, etc.

El segundo procedimiento lo vengo proponiendo desde hace años, como una forma sencilla para tomarse en serio a la persona con la que tenemos algún tipo de relaciones sexuales o amorosas; "Prima siempre la relación con la otra persona, no las conductas concretas sexuales que pudieras desear tener con ella". Dos personas pueden hacer una sola cosa o muchas muy diferentes (pasear, darse la mano, charlar, acariciarse de una u otra forma, tener relaciones coitales, sexo oral, etc.), pero: (a) lo que en concreto hagan debe ser consentido, etc. (y aplicar los principios antes expuestos) (b) y nunca debe poner en cuestión la prioridad de cuidar la propia relación, justo por anteponer como meta una determinada actividad o forma de relación (López, 2005, 2006, 2011,2012) 
Algunos ejemplos:

- Marino sale con Marta, le asegura que está enamorado, cuando no es cierto, solo para conseguir que acepte tener actividad sexual con él

- Eugenio y Laura acabaron teniendo relaciones sexuales que ella no deseaba, finalmente Laura se sintió instrumentalizada y frustrada.

El tercero es especialmente aplicable a aquellos casos en los que se plantea algún tipo de conflicto de intereses entre los miembros de la pareja ocasional o estable En este caso, el procedimiento de comunicación propuesto por Habermas (1987) es especialmente apropiado:

Principio básico: "Solo pueden pretender validez aquellas normas que pudiesen contar con el asentimiento de todos los afectados, como participantes en un discurso práctico" (Habermas, 1987, pág. 101-105).).

Para cumplir esta condición el dialogo entre afectados debe cumplir condiciones:

a) Asentimiento libre de los afectados, sin ninguna coacción, para participar en el diálogo.

b) Deben estar dispuestos a razonar en términos éticos de forma que tengan la actitud de resolver las diferencias o conflictos de forma justa, basándose en argumentaciones.

c) Tener una actitud de imparcialidad.

d) Los afectados tienen que estar en condiciones de igualdad.

e) Voluntad común de universalidad.

Finalmente, se trata de poder participar en la discusión con (a) libertad, (b) una actitud ética de querer resolver de forma justa el conflicto, (c) teniendo en cuenta los intereses, puntos de vista, argumentos, etc. del otro, (d) sabiéndose y respetándose como iguales (e) encontrando soluciones compartidas que puedan argumentarse con referencias a principios universales.

\subsection{Procedimientos específicos}

\section{- Dilemas morales}

Un dilema moral plantea el conflicto entre dos valores o situaciones que obligan a tomar una decisión argumentada éticamente.

En la vida sexual y amorosa hay numerosas situaciones en las que tenemos que decidir entre dos o más alternativas. Aprender a tenerlas en cuenta, sopesar ventajas e inconvenientes, evaluar las consecuencias de 
unas y otras, tener en cuenta los derechos fundamentales de las persona es fundamental (Kohlberg, 1984; 1992, Piaget, 1932).

\section{- Clarificación de valores}

Es una metodología en la que se proponen una serie de valores cuyo significado ético es discutido y clarificado, ayudando a descubrir los más elevados. Ha sido una forma frecuente de trabajar en la adquisición de valores. Puede aplicarse al campo de la sexualidad y las relaciones amorosas, ayudando a los participantes a concienciar los valores dominantes en la sociedad, los valores propios y aquellos que serían más deseables. Cada valor debe ser definido, analizado y sometido a argumentación, desde la perspectiva ética.

\section{- Ensayos de conducta}

Tal vez es la forma más práctica y efectiva para entrenar conductas coherentes con la ética. Normalmente se trata de la escenificación de situaciones concretas en las que se reflejan conductas inadecuadas y conductas adecuadas, se analizan las consecuencias de unas y otras. El sentido de esta forma de trabajar en la educación se basa en que ser capaz de comportarse de manera adecuada en una situación simulada hace más probable que se actúe bien en la vida real. Las tareas de generalización ayudan también a ello.

\section{Evaluación}

Es posible evaluar antes, durante el proceso de entrenamiento y después, incluso meses después, los conocimientos, la capacidad de describir conflictos de valores, el análisis de las alternativas y cuál es la decisión ética mejor argumentada y la conducta más coherente. También, bajo condiciones de anonimato, se pueden evaluar las conductas reales sexuales y amorosas que se han tenido antes y después. Por supuesto tiene también mucho sentido escuchar las valoraciones críticas de los participantes en el programa y sus propuestas para mejorarlo.

\section{3. Ética del consentimiento}

\subsection{Introducción para los alumnos o participantes en el programa}

Cada educador puede hacer la introducción que considere mejor adaptada a su grupo de trabajo, según la edad y otras características. Lo importante es motivarles y ofrecerle una primera idea de lo que se pretende.

Normalmente, estas unidades deben formar parte de un programa de educación sexual, en un contexto aún más amplio de educación para la salud, por lo que no será necesario dar explicaciones amplias (Colectivo Harimagüada, 
1991). A modo de ejemplo, con un grupo de adolescentes o jóvenes, podríamos introducir esta unidad así:

"Vamos a trabajar un terma fundamental para tener una vida sexual y amorosa satisfactorias y para aprender a no hacer daño a los demás; también para defender nuestros derechos, sin dejarnos pisar, sin dejar que abusen de nosotros, sin abusar tampoco de los demás. ¿Cómo juzgamos el que un chico viole a una chica obligándola a tener relaciones sexuales que ella no quiere, por ejemplo?, ¿O que un chico sea abusado sexualmente cuando es menor de edad?, ¿O que una mujer trabajadora sea presionada con amenazas por su jefe para tener actividad sexual? No podemos imponer un beso, una caricia sexual, una conducta sexual concreta, porque somos dueños de nuestro cuerpo, nuestra intimidad y nuestra vida sexual “ (López, 2015, 2017).

Pues de esto se trata en esta unidad didáctica: de aprender a defender nuestros derechos y a respetar la voluntad de los demás, no abusando, no acosando, no violando, etc. Y, lo que es igual de importante, aprender a respetar la libertad del otro y facilitar sus decisiones libres, justo para tener una vida sexual y amorosa mejor, más satisfactoria y más ética. Porque la ética es una ayuda para vivir mejor, en este caso las relaciones sexuales y de pareja" (López, 2015, 2017)

\subsection{Competencias u objetivos específicos}

- Entender la sexualidad y la vida amorosa como una dimensión humana que está en el "reino de la libertad", es decir que cada persona puede y debe tomar decisiones sobre su vida sexual y amorosa, sin imposiciones de nadie.

- Tomar conciencia de que el consentimiento para una actividad sexual debe ser libre, no puede ser forzado con ninguna estrategia que limite la libertad del otro, ni dejarse limitar la propia libertad.

- Adquirir la conciencia de que el cuerpo y la intimidad sexual nos pertenece ("mi cuerpo es mío, mi intimidad sexual es mía") y, por tanto, nadie debe imponernos ninguna actividad sexual o relación que no consintamos.

- Adquirir la conciencia de que el cuerpo y la intimidad sexual pertenece a cada persona ("tu cuerpo es tuyo, tu intimidad sexual es tuya") y, por tanto, no debemos imponer ninguna actividad sexual o relación a los demás.

- Aprender a analizar críticamente las diferentes formas de violación que las personas pueden sufrir: abusos a menores, acoso sexual, violación, coerción sexual con amenazas, violencia física o engaños. 
- Valorar positivamente el deseo sexual, la excitación sexual, el placer sexual, la atracción y el enamoramiento, pero con la conciencia clara de que nunca se pueden imponer a los demás conductas sexuales o relaciones amorosas que no consienten.

- Diferenciar con claridad las fronteras entre la seducción y la coerción sexual. Una cosa es seducir (legítima) y otra forzar, violar, etc.

- Conocer y analizar algunos factores que favorecen los delitos contra la libertad sexual (especialmente el consumo de alcohol o drogas, el machismo y la falta de ética sexual y amorosa) y la existencia del hecho de las agresiones sexuales, especialmente por parte de los varones.

- Aprender a definir el consentimiento como una decisión libre (sin coerciones ni engaños, en situación de lucidez y cuando se tiene edad y capacidad de consentimiento) expresada claramente.

- Valorar el consentimiento como un derecho positivo que mejora las relaciones sexuales y amorosas haciéndonos más humanos, más libres, más dignos y consiguiendo relaciones más satisfactorias. La ética del consentimiento está al servicio de la buena vida, de las relaciones satisfactorias y del bienestar nuestro y el de los demás.

\subsection{Contenidos}

El educando encuentra los contenidos de la ética del consentimiento en la exposición introductoria y, con mayor profundidad, en el libro de referencia ya citado (López, 2015).

Resumimos aquí, algunos contenidos básicos que deben acabar conociendo:

a. La ética del consentimiento como deber y como mejor manera de conseguir la satisfacción sexual y el bienestar propio y con los demás.

Ética del deber: nos sentimos obligados a respetar a los demás, como queremos que los otros nos respeten a nosotros. Todo ello en nombre del derecho a la libertad y la dignidad.

La ética de placer, la buena vida y la felicidad: cada uno de nosotros y los demás salimos ganando si somos éticos, evitamos los daños, minimizamos los sufrimientos inevitables y mejoramos la satisfacción sexual, el bienestar y la felicidad.

b. Diferentes delitos contra la libertad sexual: abusos a menores, acoso sexual, violación y coerción sexual. 


\section{Abusos sexuales a menores}

Cuando un adulto o un menor (a) con una asimetría de edad o nivel de desarrollo o (b) sirviéndose de coerción o engaños, involucra a un menor de edad, que no consiente (o que no puede consentir porque es muy pequeño o tiene alguna discapacidad), en alguna actividad sexual.

La asimetría de edad la definen algunos códigos penales, aunque es discutible poner intervalos de edad concretos. Pero, en todo caso, es evidente que, por ejemplos, un hombre de 50 años tiene una alta asimetría de edad con un menor; y un chico de 14 también tiene una alta asimetría de edad con uno de 5 años.

\section{Acoso sexual}

Cuando alguien se sirve de su poder laboral, docente o similar, doblegando la voluntad de la otra persona o poniendo muchas dificultades al uso de su libertad, para conseguir tener actividad sexual con ella.

Un empresario o capataz con una empleada o empleado, un profesor con un alumno, un médico con un paciente, que se sirven de su poder, son casos de acoso porque la víctima puede sufrir consecuencias negativas, recibir premios o castigos que consigan hacer doblegar su voluntad.

$\mathrm{Si}$, por ejemplo, un profesor le dice a una alumna o alumno que no le aprueba, si no accede a tener relaciones con él, está cometiendo un acoso sexual.

\section{Violación}

Este concepto pone el acento en la conducta que se impone a la otra persona, coito vaginal, anal o sexo oral, tal como lo define el código penal.

Pero, en realidad, toda caricia o conducta sexual impuesta es una vulneración de la libertad del otro y por tanto susceptible de ser denunciada y, desde luego, un grave atentado a la ética sexual y amorosa.

\section{Coerción o engaños sexuales}

Es un concepto con límites menos precisos, se refiere a toda forma de violencia física, verbal o engaños que limitan o llegan a impedir la libertad de la otra persona.

La ética va mucho más allá, porque la conducta adecuada debe entenderse como un valor positivo que implica no solo el evitar toda forma de 
coerción, sino facilitar la decisión libre del otro (Gómez-Zapiain y Pinedo, 2012)

\section{c. Concepto de consentimiento.}

El consentimiento supone que la persona decide hacer o dejar hacer al otro una conducta (en este caso una conducta o relación amorosa) aceptándola. Supone la libertad para decir sí o no, así como la autonomía de quién consiente y el conocimiento de lo que es la actividad y sus posibles efectos o consecuencias.

Las leyes (en este caso el código penal) suelen definir la edad a partir de la cual se supone que un menor puede consentir tener actividades sexuales. El español, por ejemplo, la sitúa ahora en los 16 años; hasta hace poco eran los 13 años y llegó a estar en los 12 años.

Creemos que, al menos Europa debería tener una misma edad de consentimiento, por numerosas razones. Entre ellas, porque tenemos libertad de movimiento, hay muchos intercambios turísticos y laborales, etc., por lo que es absurdo que lo que se condena con cárcel en unos países no sea delito en otros.

\subsection{Principio universal de la ética del consentimiento}

En las relaciones sexuales y amorosas debemos tratarnos reconociendo siempre la dignidad y libertad propia y de la pareja, nunca instrumentalizando al otro/a buscando únicamente el propio provecho, de forma que tanto nosotros como la otra persona nos sintamos libres de aceptar o no esas relaciones.

Se puede hacer un comentario de los contenidos de este principio en el que quede claro para los alumnos:

- ¿De qué conductas y relaciones estamos hablando?: conductas sexuales de todo tipo (besos, caricias, coitos, cogerse de la mano, acariciar cualquier parte del cuerpo, proximidad física socialmente considerada inadecuada, piropos ofensivos, de mal gusto o que la otra persona rechaza, observar la intimidad del otro, hacer o distribuir fotos íntimas, contar posibles secretos íntimos del otro, exhibirse sexualmente ante el otro, perseguir, presionar, acoso por Internet, etc.).

- ¿Cuáles son los valores de referencia?: la libertad y la dignidad, la propiedad de la persona sobre su cuerpo e intimidad, el respeto, la evitación del daño y el dolor al otro y las relaciones satisfactorias con el otro. 
Los contravalores suponen una instrumentalización del otro a favor de los propios deseos, tratando al otro como un objeto, no como una persona con derechos, libertad y dignidad.

- ¿Cuáles son las condiciones de la libertad?: poder decir "sí o no", sin coerción física o verbal, sin engaños sobre los sentimientos y compromisos, conociendo las consecuencias, sin daños o castigos como consecuencia de un "no".

\section{Factores y situaciones de riesgo frecuentes que favorecen la violación de éste principio}

Todo lo que amenace la lucidez sobre los argumentos y las decisiones, por anulación total o parcial de la conciencia y la capacidad de reflexión, así como todo lo que puede favorecer que la voluntad decida contra los propios valores e intereses o sin tener en cuenta el consentimiento de la otra persona, debe considerarse factor de riesgo.

El listado podría ser muy grande, señalamos solo algunos de estos factores:

- Asimetría amplia de edad.

- Consumo de alcohol u otras drogas.

- Presión del grupo de iguales para tener relaciones o asumir riesgos que amenazan la conducta libre y responsable.

- No considerarse activo sexualmente y, sin embargo, serlo en determinadas situaciones.

- Necesidades económicas apremiantes o valoración excesiva del dinero fácil, lo que puede forzar el consentimiento como ocurre con la prostitución.

- Nuevos mitos sobre sexualidad (analizar con los alumnos el texto incluido sobre ello al final de la introducción), como el de la necesidad de actividad sexual para tener salud, etc.

- Consumo de pornografía infantil (en todos los casos) o de pornografía adulta por parte de menores sin educación sexual.

- Participar de ideas machistas: supuesta superioridad sobre las mujeres, menosprecio de las mujeres, doble moral sexual, sentimiento de propiedad sobre las mujeres, relaciones de poder-sumisión en la pareja, etc. 
- Los factores de riesgo específicos de los abusadores o agresores sexuales pueden revisarse con más detalle en otras publicaciones (López, Carpintero, Del Campo Lázaro, y Soriano, 2011).

\subsection{Ejemplo de algunas actividades}

\subsubsection{Mi cuerpo es mío, mi intimidad es mía, mi sexualidad es mía y, por tanto, tu cuerpo es tuyo, tu intimidad es tuya, tu sexualidad es tuya}

Actividad fundamental para tomar conciencia de la propiedad del cuerpo, la intimidad y la propia biografía sexual y amorosa, así como, en reciprocidad, que el cuerpo de los demás es suyo, no nos pertenece. En esta actividad se trabajan especialmente los conceptos de libertad y consentimiento, como presupuestos de todo intercambio sexual y amoroso, porque el cuerpo y la intimidad sexual nos pertenece.

Es una tarea también de prevención frente a los abusos sexuales a menores, el acoso sexual, la violación y toda forma de coerción, útil también en relación con los agresores y las víctimas.

\section{Objetivo}

Comprender la esencia de lo que debemos conocer y cómo hemos de comportarnos en la conducta en las relaciones sexuales y amorosas, basándonos en dos argumentos básicos: la libertad de los participantes y la propiedad del cuerpo, puesto que somos corporales.

\section{Descripción}

- Se ponen de pie, se hacen unos breves ejercicios de relajación con la respiración, la posición corporal y la tensión-relajación de la musculatura.

- Se pide concentración en uno mismo, puede facilitarla cerrar los ojos.

- Se repiten en voz alta, a coro, las frases que va diciendo el educador o monitor (deben decirse de forma lenta, con énfasis que expresen convencimiento, y dejando unos segundos una vez que se ha repetido a coro); a la vez se van tocando las partes del cuerpo citadas, tomando conciencia de que nos pertenecen.

\section{Prima parte}

- $\quad$ Todo mi cuerpo es mío.

- Mi pelo es mío.

- Mi frente, mi nariz y mis ojos son míos.

- Mis orejas son mías.

- Mi boca es mía. 
- Mi sexualidad es mía.

- Mi intimidad sexual es mía.

- Mi biografía sexual y amorosa es mía.

- Mi cuello es mío.

- Mis hombros, mis brazos y mis manos son míos.

- Mi espalda es mía.

- Mi pecho es mío.

- Mi sexualidad es mía.

- Mi intimidad sexual es mía.

- Mi biografía sexual es mía.

- Mi vientre es mío.

- Mis glúteos son míos.

- Mis genitales son míos.

- Mi sexualidad es mía.

- Mi intimidad sexual es mía.

- Mi biografía sexual es mía.

- Mis piernas y mis pies son míos.

- Soy dueño o dueña de mi cuerpo, mi intimidad y mi vida amorosa, nadie puede acceder a mi sexualidad sin mi consentimiento.

A continuación se les pide que se pongan por parejas, uno frente al otro. $\mathrm{Y}$ deben repetir las siguientes frases a la vez que las señalan en el cuerpo del otro:

- Todo tu cuerpo es tuyo.

- Tu pelo es tuyo.

- Tu frente, tu nariz y tus ojos son tuyos.

- Tus orejas son tuyas.

- Tu boca es tuya.

- Tu sexualidad es tuya.

- Tu intimidad sexual es tuya

- Tu biografía sexual y amorosa es tuya

- Tu cuello es tuyo.

- Tus hombros, tus brazos y tus manos son tuyos.

- Tu espalda es tuya

- Tu pecho es tuyo.

- Tu sexualidad es tuya.

- Tu intimidad sexual es tuya. 
- Tu biografía sexual es tuya.

- $\quad$ Tu vientre es tuyo.

- Tus glúteos son tuyos.

- Tus genitales son tuyos.

- Tu sexualidad es tuya.

- Tu intimidad sexual es tuya.

- Tu biografía sexual es tuya.

- Tus piernas y mis pies son tuyos.

- $\quad$ Eres dueña de tu cuerpo, tu intimidad y tu vida amorosa, nadie puede acceder a tu sexualidad sin tu consentimiento.

\section{Análisis y trabajo posterior}

Al acabar se les puede pedir que comenten con su pareja como se han sentido, hasta qué grado se es consciente de la propiedad del cuerpo y, sobre todo, hasta qué grados creen que, entre las personas de su edad, se respeta la propiedad del cuerpo y la intimidad sexual.

Advertimos también que es una situación docente y, por tanto, no se debe preguntar si han impuesto conductas sexuales a otras personas o si han sido víctimas.

Defender la propiedad del cuerpo y espetar el cuerpo de los demás es nuclear para prevenir toda forma de violencia sexual.

\section{Dos conceptos y valores deben quedar claros: el de libertad y el de consentimiento}

Se les pueden plantear preguntas como: ¿Qué consecuencias sacáis de esta actividad?, ¿Podéis poner ejemplos de violación o falta de respeto de esta propiedad?, ¿Qué principio o valores éticos son vulnerados si no hay consentimiento?, ¿Qué es lo más característico de la sexualidad humana a diferencia de la sexualidad animal?, etc.

\section{Aplicación a los casos penales más graves}

Lamentablemente es frecuente que esta propiedad del cuerpo y la intimidad sea violada, con violencia, engaños o estrategias diversas. El 10\% de los niños y el 20\% de las chicas han sufrido abusos siendo menores, el acoso sexual es frecuente y las violaciones son cometidas con frecuencia por un amigo, la pareja o el esposo".

Es el momento de explicar por primera vez en el programa estos conceptos (abuso, acoso, violación, coerción), poner o que pongan ejemplos que han conocido por alguna vía (no se pregunta por la experiencia personal) y analizar las posibles consecuencias. 


\section{Un buen tema de debate}

¿Qué condiciones concretas exige el consentimiento?: ¿cómo puedo saber que el otro consiente?, ¿basta con callar, porque el que calla otorga?, ¿basta con fiarse de la comunicación no verbal y cómo debería ser ésta para estar seguros de que se consiente?, ¿es necesario tener un "sí" verbal expreso?, los jueces deben preguntar simplemente si la supuesta víctima no dijo "no" (suponiendo que quien calla otorga) o deberían preguntar si dijo expresamente "sí" y de qué forma.

\section{Acabar en positivo}

Esta actividad también y sobre todo se hace para favorecer las relaciones consensuadas, porque son las éticas, las satisfactorias para ambos, las verdaderamente humanas.

Puede pedírsele que recuerden experiencias sexuales y amorosas consentidas que fueron muy satisfactorias. Este recuerdo pueden hacerlo de forma íntima, o pedirle que lo hagan en su casa, cuando estén solos, etc.

Una manera de reforzar esta idea es pedirles que digan las ventajas de las relaciones sexuales consentidas, con énfasis en las consecuencias positivas para la propia actividad sexual y para las relaciones de pareja.

\section{Tareas de generalización}

A lo largo de la semana siguiente, se les pide que:

a. Cuenten esta actividad a alguien explicándole lo que significa. Podría ser idealmente a pareja, los padres, algún familiar cercano, algún amigo o amiga que no la conozca, etc.

b. Detectar o recordar casos cercanos (o que los lean en los medios de comunicación) de vulneración de la ética del consentimiento.

c. Revisar en privado (no se preguntará por ello) su biografía sexual y amorosa desde la perspectiva de este principio.

d. Si se da la ocasión, planearse en la relación la forma de saber con seguridad si el otro y otra consiente.

Por ejemplo, uno chico de 20 años, me ha escrito diciéndome que al leer el libro de Ética de las relaciones Sexuales y Amorosas, se ha dado cuenta que había cometido muchos errores en sus relaciones con las chicas, y no se trata de un violador.

\subsubsection{La diferencia entre la seducción y la coerción y los engaños}

Se trata de una actividad para hacer reflexionar sobre la difusa frontera entre determinadas conductas de seducción y la coerción o los engaños. 


\section{Objetivos}

- Defender la bondad y el derecho a la seducción, salvo que ésta conducta sea expresamente rechazada por la persona objetivo de dicha conducta.

- Diferenciar la seducción de cualquier forma de coerción o engaño.

- Reconocer el derecho de la otra persona a responder con un "sí o un no" a la seducción.

- Tomar conciencia que todo abuso, acoso, violación deben ser denunciados. Denunciarlo si se ha sufrido o animar a denunciarlo a quienes nos comunican este mal secreto, que debo contribuir a romper.

\section{Concepto de seducción}

Se refiere a todas las conductas que una persona pone en juego para llamar la atención de otra persona (miradas, palabras, proximidad física, ciertos contactos corporales convencionalmente aceptables, citas, llamadas, correos, regalos, invitaciones, etc.) con las que se pretende provocar una atracción recíproca, una comunicación más abierta $\mathrm{y}$, tal vez, la aceptación de determinadas conductas sexuales o el inicio de relaciones afectivas con contenido sexual y amoroso.

La seducción debe considerarse una conducta legítima si la otra persona acepta estas conductas y mantiene su libertad para responder en un sentido u otro

\section{Concepto de coerción}

Conductas físicas o verbales que sobrepasan la frontera de lo aceptable socialmente, presionan o pretenden obligar a la otra persona a aceptar una determinada conducta sexual o relación amorosa que en condiciones de libertad no aceptaría. También se produce una coerción a la libertad cuando se engaña sobre lo que se pretende, se promete lo que no se piensa cumplir, etc.

La violencia física o verbal, el uso de poder en situaciones de acoso o el abuso de confianza como estrategia para vulnerar la libertad del otro son el extremo más inaceptable de la coerción.

\section{Análisis de casos}

- Oscar y Matilde coinciden en un bar. Oscar está a unos metros de ella, no la conoce, pero se siente interesado por ella. La mira una y otra vez, ella empieza a devolverle la mirada y acaba sonriéndole, él se acerca y entablan una conversación, toman algo juntos, bailan y finalmente salen del lugar encantados.

- Daniela es la jefa de Andrés. Trabajan en la misma empresa y Daniela intenta seducir a Andrés (que de entrada se muestra confuso y remiso); entre otras cosas le dice que si sale con ella le mejorará el sueldo. 
- Iván es compañero de clase de Cecilia, lleva tiempo intentando seducirla; ha llegado a ser muy reiterativo y pesado. Ella ya le ha dicho claramente que la deje en paz, que no le gustan las cosas que le dice y no acepta salir con él.

- Un profesor quiere salir con una alumna y tener relaciones sexuales con ella. Ella se asusta, pero no sabe muy bien qué decir. Él le dice que no hay tanta diferencia de edad y que quiere que sea su novia y más tarde su mujer, pero no tiene ninguna intención de cumplir esta promesa, solo desea tener relaciones con ella.

- Un compañero de clase le dice a una compañera cosas tan explícitas y mal educadas (en un caso real que nos llego le decía cosas como "te echaría un polvo aquí mismo, sobre la mesa del profe", etc.) que ésta se siente acosada. Se queja abiertamente y llora cuando éste persiste.

- Los alumnos pueden proponer otros ejemplos de seducción aceptable y no aceptable, así como de coerción o engaño. Casos que han conocido por algún medio.

Se analizan los casos en grupos mixtos, entre cinco y siete componentes, y después se ponen en común los argumentos por lo que una conducta es éticamente aceptable o no, así como legalmente punible. Definir también, en los casos punibles, la figura penal.

\section{Temas de debate}

- ¿Son aceptables los piropos?: ¿qué es un piropo?, ¿hay diferentes tipos de piropos?, ¿deben ser evitados todos o hay algunos que podrían aceptarse, en este caso, bajo qué condiciones?

Tal vez pueda ser útil hacer primero una discusión por sexos y luego en grupos mixtos.

- ¿Cómo son las formas de seducción a través del móvil o de internet?: ¿Más directas o más brutales?, ¿Podrías señalar los malos usos de internet o de los móviles en las relaciones sexuales y amorosas?

\section{Actividades de generalización}

- Pedir de forma amable y clara una cita, aceptando de buen grado el "sí o el no".

- Manda un mensaje por el móvil que pueda considerarse un piropo aceptable.

- Toma nota de formas de seducción o piropos inaceptables que hayas escuchado u observado, que de hecho son rechazados por la persona a la que van dirigidos. 
- (Tarea personal) Revisa la historia de tus seducciones o cuando tú has sido el objeto de seducción y valóralas éticamente.

\subsubsection{Dilemas}

Se trata de plantear dilemas que ayuden a los alumnos a descubrir posibles valores en conflicto y situaciones que obligan a argumentar entre una y otra alternativa, con el fin de que aprendan unos de otros a argumentar desde la ética del consentimiento.

\section{Objetivos}

- Analizar los dilemas y sus diferentes alternativas.

- Argumentar a favor de la alternativa más ética.

\section{Supuestos}

Analizar y argumentar bien es el primer paso y condición para decidir bien, formar la "buena voluntad". Decidir bien puede ayudar a comportarse bien, evaluar después la propia conducta y sentirse más motivado para cambiarla si no ha sido adecuada.

Si el grupo no es muy activo, dividirlo en pequeños grupos, como paso previo o plantearle preguntas como: ¿qué suelen hacer los hombres en un caso así? ¿Y las mujeres si fuera a la inversa?, ¿Qué alternativas tienen y cuáles son sus posibles consecuencias? Y la fundamental: ¿qué debería hacer Marcos (o Margarita en la situación inversa) y por qué?

\section{Algunos dilemas o situaciones}

- Un hombre desea y disfruta mucho del sexo oral, si se lo hace su pareja. Pero ella siente asco y lo rechaza, "me dan ganas de vomitar y de hecho tengo arcadas".

- El hombre presiona y acaba abusando de su mujer obligándola incluso por la fuerza a tener conductas sexuales que ella no quiere.

- Una chica adolescente le dice a un chico, que rechaza tener relaciones con ella, que si no quiere acostarse con ella es porque no es realmente un hombre o porque no la quiere, presionándole para que ceda, etc.

- Un amigo fuerza a una mujer a tener relaciones coitales que ella rechaza negándose explícitamente. (No olvidar que las violaciones por amigos, conocidos y esposos son las situaciones más frecuentes de esta conducta, a pesar que lo noticiable sean las violaciones de desconocidos, excarcelados, etc.). 


\section{Temas de debate}

Puede hacerse una discusión sobre ciertas estadísticas preocupantes. Por ejemplo, un número importante de las chicas aseguran que ellas, en realidad, no querían tener la primera relación sexual cuando de hecho sucedió. Pero la insistencia de su pareja, ocasional o estable, hizo que acabara cediendo. Aseguran que no fue una violación, porque finalmente cedieron y aceptaron la relación, pero lo hicieron, por diferentes razones: "se puso muy pesado", "tenía miedo de perderle", "para él era muy importante", "no me considera una estrecha", "casi todas las de mi edad ya lo habían hecho, etc.

¿Qué valoración te merecen estos datos?, ¿podríamos educar mejor para que las relaciones fueran lo más libres y dignas posibles?, ¿qué habilidades sociales deberíamos promocionar para evitar estos datos?

\section{REFERENCIAS}

Beck, U. y Beck, P. (1999). El normal caos del amor. Barcelona: Paidos.

Colectivo Harimagüada (1991). Carpetas didácticas de Educación Afectivo-Sexual. Vol. I, Infantil; Vol. II, Primaria; Vol. III, Secundaria. Conserjería de Educación, Cultura y Deportes: Gobierno de Canarias.

Cortina, A, (2010). Neuroética. ¿Las bases cerebrales de una ética universal con relevancia política? Isegoria, 42, 29-48.

Gómez-Zapiain, J., y Pinedo, J. A. (2012). Programa de integración de la educación sexual en el proyecto curricular. Guía para el profesorado. Vitoria - Gasteiz: Servicio publicaciones Gobierno Vasco.

Recuperado de: www.uhinbare.com/index.php/es/dokumentuak

Gómez-Zapiain, J. (2012). Sexumuxu. Programa interactivo de educación sexual para adolescentes. Vitoria-Gasteiz: Servicio de Publicaciones del Gobierno Vasco. Recuperado de: www.uhinbare.com

Habermas, J. (1987; 1991, edición en castellano). Escritos sobre la moralidad y la eticidad. Barcelona: Paidós.

Habermas. J. (1983; 1985 versión en castellano). Conciencia moral y acción comunicativa. Barcelona: Península.

Iribartren, M. A. (2002). Una propuesta de educación sexual para una sociedad éticamente plural. Tesina de licenciatura. Madrid: Universidad Pontificia de Salamanca.

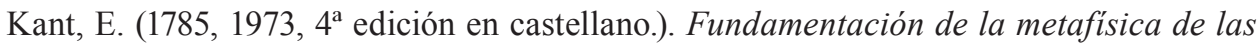
costumbres. Madrid: Austral.

Kant E. (1785). Metafísica de las Costumbres. Madrid: Austral.

Kohlberg, L. ( 1984; 1992, versión en castellano). Psicología del desarrollo moral. Bilbao: Desclée de Brouwer.

López, F (2005). Educación sexual. Madrid: Biblioteca Nueva. 
López, F. (2006b). Homosexualidad y familia. Barcelona: Grao.

López, F. (2009). Amores y Desamores: procesos de vinculación y desvinculación sexuales $y$ afectivos. Madrid: Biblioteca Nueva.

López, F., Carpintero, E.., Del Campo A., Lázaro, S. y Soriano, S. (2011). Menores infractores: programas educativos y terapéuticos. Madrid: Pirámide

López, F. (2011). Separarse sin grietas: como sufrir menos y no hacer daño a los hijos. Barcelona: Grao.

López, F. (2012). Sexualidad y afectos en la vejez. Madrid; Pirámide.

López, F. (2015). Ética de las relaciones sexuales y amorosas. Madrid: Pirámide.

López, F. (2017). Educación sexual y ética de las relaciones sexuales y amorosas. Unidades didácticas. Madrid: Pirámide.

Piaget, J. (1932). La jugement moral chez l'enfante. Paris: Alean.

Seligman, M. (2011). La auténtica felicidad. Barcelona: Zeta. 